\title{
Single-use medical devices: economic issues
}

\author{
Philip Jacobs, ${ }^{1}$ Ilke Akpinar ${ }^{2}$
}

\section{THE SIZE OF THE MEDICAL NEW-DEVICE AND REUSE MARKETS}

Evaluate MedTech estimated that worldwide sales of medical devices in 2017 were US\$386.8 billion. Cardiology was among the largest groups, with $\$ 44.6$ billion in sales. ${ }^{1}$ The Emergo Group estimated US sales to be $\$ 147.7$ billion and sales in India to be $\$ 3.5$ billion. $^{2}$ The average annual growth of the device market since 2009 has been about $16 \% .^{3}$

Although many devices have been labelled as 'single-use' by the original manufacturers, some of these have nonetheless been reprocessed and used again. Some device manufacturers have warned against this practice, ${ }^{45}$ ostensibly because of the potential risks of infection or breakdown. For some time, hospitals have been reprocessing SUDs in-house. Also, since about the year 2000 a thriving third-party reprocessing industry has emerged in North America and Europe. Only about $2 \%-3 \%$ of all devices can be safely reprocessed. ${ }^{6}$ By 2016, global revenue of independent SUD reprocessors was estimated to be $\$ 1.054$ billion. $^{7}$ Estimated sales of third-party reprocessors in the USA was $\$ 848.5$ million. $^{8}$ In-house hospital activities are generally not included when considering the size of the reprocessing marketplace. In India, there is considerable in-house activity in device reprocessing in hospitals, ${ }^{9} 10$ but there is no large-scale SUD third-party market.

\section{ECONOMIC APPROACH TO ANALYSIS OF REUSE}

We compare the difference in cost with the difference in harm between new and reused SUDs. The variables included in this comparison are shown in table 1 . These variables are defined differently between countries because the markets and regulatory systems are so different.

\section{REGULATION AND THE RISKS OF REPROCESSING}

The risk of harm is the major clinical outcome for reprocessing activity. To help regulate the safety of brand new and reprocessed devices, The US Food and Drug Administration (US FDA) developed a three-class licensing system. ${ }^{11}$ Devices in the 'no-critical' Class I pose a minimum risk of harm for the user; $47 \%$ of devices fall in this category and most are exempt from regulation, but manufacturers must register the device with the US FDA. Those in the 'semicritical' Class II-about 43\% of all devices-bear some or unknown risk. A manufacturer must apply to the US FDA for approval by demonstrating equivalence in risk to an existing device using a request based on section $510 \mathrm{k}$ of the US FDA Act. A Class III 'critical' device is one with higher or unknown risk such as an interventional device; the manufacturer must apply for Pre-Market Approval and the application must include clinical evidence of safety and effectiveness. About $10 \%$ of devices fall into this category. Devices that are labelled as 'SUD' but are reprocessed and reused are treated in the same way as those that have not previously been used; manufacturers-in this case, reprocessors-of Classes II and III reprocessed devices must make applications to the US FDA similar to those made by the manufacturers of original devices. This holds both for third party reprocessors and for hospitals which are doing their own reprocessing. Reprocessors must label and track reprocessed devices. It seems that this regulatory system has worked quite well and there were very few examples of reprocessed devices which caused harm. ${ }^{11}$

In 2017, India revised its regulatory system for the importation and manufacture of medical devices. The Central Drugs Standard Control Organization of the national Ministry of Health and Family Welfare lists four classes of devices and identifies specific devices in each; these are: class A (low risk), class B (lowmoderate risk), class $\mathrm{C}$ (moderate-high risk) and class $\mathrm{D}$ (high risk). A manufacturer of class $C$ and D devices must register with the Drug Controller General of India, within the Ministry of Health and Family Welfare, and conduct appropriate tests before receiving approval. In India, there is no regulation for reuse; the Drugs and Cosmetics Act (rule 65.17) states that devices must be used according to their labels. Nevertheless, there is considerable reprocessing in India, but it is done in-house. ${ }^{10}$ There has not been much tracking of reused devices, so there is little information about outcomes.

\section{PRICING MEDICAL DEVICES}

The economic aspect of device use in the USA has focused on the prices paid by the healthcare providers to manufacturers. In North America, these wholesale (ex-factory) prices of both new and reused medical devices are the result of negotiations between hospitals and manufacturers (which includes third party reprocessors) in a competitive market setting. There is no regulation of wholesale prices. The prices charged by manufacturers of medical devices are usually confidential and can vary widely, even between different customers who purchase the same product; however, the presence of purchasing consortiums enhance the role of competition in setting prices. Nevertheless, there has been a considerable amount of public interest in medical device pricing in recent years. Much of this interest has centred around the value of the product, and the degree to which the wholesale price-the price paid to the manufacturer by the hospital-reflects 'value'. ${ }^{12}$ In particular, when there is product differentiation between brands for a similar product, it is difficult to put a value on product characteristics. Waste management issues, on the other hand, which affect the costs of the reuse decisions, are not considered to be material.

\footnotetext{
${ }^{1}$ Faculty of Medicine and Dentistry, Institute of Health Economics, University of Alberta, Edmonton, Alberta, Canada

${ }^{2}$ Public Health, University of Alberta, Edmonton, Alberta, Canada

Correspondence to Dr Philip Jacobs, Faculty of Medicine and Dentistry, Institute of Health Economics, University of Alberta, Edmonton, AB T6G 2G3, Canada; pjacobs@ihe.ca
}

Table 1 Variables used for economic analysis of reuse in the USA and India USA India

Resource indicators The ratio of new to reuse price, based on the prices paid by the healthcare provider to the manufacturer.

Comparison between new and reused retail prices charged to patients; hospital trade margin on new and reused devices.

Safety/efficacy Number of reused devices classified and No data.

indicators tracked for harmful effects. 
In North America, the retail price of new medical devices-the price paid by the consumer, government health plan, or the third party insurer-is usually part of the overall price of the entire medical product such as a hospital stay or an outpatient procedure. In this case, there is no identifiable retail price for a component product like a balloon catheter: that is because many US hospitals are paid a single price for the entire stay or visit.

In India, hospitals set separate prices for each drug and consumable (including devices), room rents and doctors' services. The drug and consumables category of costs makes up between $30 \%$ and $50 \%$ of total expenses. ${ }^{13}$ Unlike in North America, the prices of medical devices in India are semiregulated. For example, there is a maximum retail price (MRP) placed on most goods in India, although in many cases this maximum price is set very high and may not reflect the price the consumer actually pays. The MRP in some cases is as much an advertising tool (indicating a 'discount' if the consumer pays less) as a regulated ceiling. The same is not true for the regulation of the prices of necessary drug. The prices of a category of drugs that are deemed to be necessary drugs (and which are listed in the National List of Essential Medicines) are regulated by the National Pharmaceutical Pricing Authority (NPPA) of the Ministry of Chemicals and Fertilizers. The NPPA has also added some medical devices to the list, including catheters, and has placed retail price caps on a few of these products. In 2017, the retail price of stents was found to be very high in private hospitals and so the NPPA set maximum prices on stents. ${ }^{14}$ The NPPA also examined wholesale and retail prices of some other devices, including catheters; an NPPA report in early 2018 found that 'profit margins on non-scheduled devices (syringes, cannula and catheters) are exorbitant and clearly a case of unethical profiteering in a failed market system'. ${ }^{15}$ The NPPA report noted that trade groups were calling for government action, though they stated that price caps, if they are rigidly set (as in the case of stents), might impede innovation on new products which had legitimately higher prices; they called for caps on trading margins-rather than MSPs-which would rein in retail prices charged by the hospitals ${ }^{16}$ while not affecting the wholesale or ex-factory price.

There is an active retail market for reused medical devices in India. At about the same time as the NPPA investigation on prices of new medical devices, information was coming out about high prices being charged to patients for reused devices; a report by the Maharashtra FDA revealed that some private hospitals were charging patients for reused catheters at $77 \%$ of the MRP: ${ }^{17} 18$ used balloon catheters with an MRP of 26000 rupees were being priced at 20000 rupees. As there is no separate price cap for reused devices, this practice leaves pricing policies for reusable devices wide open. According to the Hindustan Times, charging nearMRP prices for SUDs may be unethical, but '...the Medical Council of India, health ministry or FDA has no legal provisions to stop...' it. ${ }^{17}$ Nevertheless, following the Maharashtra FDA investigation the police filed a first information report on pricing of reused devices. In the absence of a market for reprocessing and without any clear regulations about reprocessing, the situation regarding reusable devices in India remains a jumble. ${ }^{19}$

\section{STANDARDS FOR PRICING REUSABLES}

A variable that has captured attention recently is the relationship between the price of a brand new device and that of a reconditioned one. In the USA, the price of the new device refers to the wholesale price paid by the hospital to the manufacturer; the price of the reused device refers to the price paid to a reprocessor. The ratio of the price paid by the hospital for new devices, compared with that of reused devices, is somewhere around 2 to $1 .^{20}$ Sometimes the price of the reused device is the cost the hospital incurs by doing its own reprocessing in-house; other times it is the wholesale price paid to a reprocessor who does the reprocessing. Usually, the hospital's own reprocessing cost is considerably lower than the price set by a third party reprocessor, although in the USA all reprocessing must meet stringent regulatory standards and therefore incur considerable costs.

Although there is a standard ratio of new to reused devices in the USA, there are factors that influence this ratio. The ex-factory (new device) price will be influenced by the design of the device. In addition, the ex-factory (new) price will vary because of the competitive process. Ex-factory prices differ somewhat because of purchasing factors such as volume discounts and the use of purchasing agents. The price of the reused device will also vary. A major determinant of the cost of a reused device is the number of times that the device is reused. Authors in the $\mathrm{USA}^{21}$ indicate that the number of times a catheter is reused varies considerably, with one-half of the devices being reprocessed
5 times or less. In India, authors ${ }^{9}$ have estimated a desired range of reuses of between 2 and 5 times. We should note that the actual cost of reprocessing for any device-that is, the resources that go into the reconditioning process itself - will not change if the wholesale or ex-factory price for a specific device is lowered, so there is probably some wholesale price for a new device below which the cost of reprocessing will not be worth it.

These factors might have some relevance to the retail reprocessing price in India. As reprocessing activity moves forward in India, hospital retail (charged to consumers) prices of reused devices will emerge. The USA standard ratio of wholesale prices to reused prices can be used as a benchmark, at least initially, because this ratio has become established in a competitive market setting.

Indian hospitals have already set retail prices for reused devices, but these do not seem to bear any relation to the resources that go into the refurbishing process. Currently, because of the item-by-item hospital payment system in India, Indian private hospitals have an incentive to increase charges to near-MRP levels, even for reused devices. This has raised the prospect of government regulators such as NPPA controlling retail prices for reuse, as well as new, devices.

\section{CONCLUSION}

When we compare the reuse versus new-use-only for SUDs, there are two aspects to the issue: price (cost) and risk of harm. In developed countries, the policy focus has been on the health outcomes of the alternative approaches and on ways to influence these outcomes through regulation. More recently, western policymakers have been focusing on value, which is an outcome-based, rather than a resource indicator. In India, the regulatory focus has been on the prices charged for medical devices and on the regulation of these prices. These differences between USA and India approaches have emerged because of differences in the healthcare payment systems. Pricing regulation for new devices is increasing in India and will likely be extended to cover reused devices. Regulators will have to adapt target variables to meet the Indian circumstances. The use of standards obtained from the US devices market is a good starting point.

Contributors PJ participated in initial search and did first and last drafts. IA participated in initial data search and in first and final drafts. 
Funding The authors have not declared a specific grant for this research from any funding agency in the public, commercial or not-for-profit sectors.

Competing interests None declared.

Patient consent Not required.

Provenance and peer review Commissioned; internally peer reviewed.

(c) Article author(s) (or their employer(s) unless otherwise stated in the text of the article) 2018. All rights reserved. No commercial use is permitted unless otherwise expressly granted.

\section{D) Check for updates}

To cite Jacobs P, Akpinar I. Heart Asia 2018;10:e011034. doi:10.1136/ heartasia-2018-011034

\section{CLinked}

- https://doi.org/10.1136/heartasia-2018-011033

Heart Asia 2018;10:e011034. doi:10.1136/ heartasia-2018-011034

\section{REFERENCES}

1 Evaluate MedTech. World preview 2017, outlook to 2022. Executive summary. 2017. http://info. evaluategroup.com/rs/607-YGS-364/images/ EvaluateMedTech-World-Preview-2017-ExecutiveSummary-ES.pdf (accessed Mar 2018).

2 Emergo. UK overview of medical device industry and healthcare statistics. 2018. https://www.emergogroup. com/resources/market-united-kingdom (accessed Mar 2018).
3 World Health Organization. 2017. http://www.who.int/ en/ (accessed Mar 2018).

4 United States Government Accountability Office. 2000 Single-use medical devices. Washington: GAO. https:// www.gao.gov/products/GAO/HEHS-00-123 (accessed Mar 2018)

5 Eucomed. Eucomed white paper on the reuse of single-use devices. 2009. http://www.medtecheurope. org/sites/default/files/resource_items/files/15122009_ MTE_Eucomed\%20White\%20Paper\%20on \%20the\% 20reuse $\% 20$ of $\% 20$ single $\% 20$ use $\% 20$ devices_ Backgrounder.pdf (accessed Mar 2018).

6 Medical Dealer. Single-use device options- promoting cost savings and infection prevention. 2016. http:// medicaldealer.com/29139-2/ (accessed Mar 2018).

7 Coherent Market Insights. Reprocessed medical devices - low on cost, high on quality. 2017. https:// www.coherentmarketinsights.com/market-insight/ reprocessed-medical-devices-market-234 (accessed Mar 2018)

8 Transparency Market Research. Global reprocessed medical devices market: snapshot. 2017. https://www. transparencymarketresearch.com/reprocessed-medicaldevices.html (accessed Mar 2018).

9 Kapoor A, Vora A, Nataraj G, et al. Guidance on reuse of cardio-vascular catheters and devices in India: a consensus document. Indian Heart J 2017;69:357-63.

10 Hussain M, Balsara KP, Nagral S. Reuse of single-use devices: looking back, looking forward. Natl Med J India 2012;25:151-5.

11 United States Government Accountability Office. Reprocessed Single-Use Medical Devices. FDA Oversight Has Increased, and Available Information Does Not Indicate That Use Presents an Elevated Health Risk. Washington: GAO, 2008.

12 Provines CD. Strategic Pricing for Medical Technologies: A Practical Guide to Pricing Medical Devices \& Diagnostics. 32: Amazon, 2012.

13 Times of India. Drugs, consumables $30-50 \%$ of hospital bills, doc fees 10-20\%. 2017. https:// timesofindia.indiatimes.com/india/drugs-consumables- 30-50-of-hospital-bills-doc-fees-10-20/articleshow/ 62288176.cms (assessed Apr 2018).

14 Times of India. Cardiac stent price cap lowered further to Rs 28,000. 2018. https://timesofindia.indiatimes. com/india/cardiac-stent-price-cap-lowered-further-tors-28000/articleshow/62889521.cms (accessed Mar 2018).

15 National Pharmaceutical Pricing Authority [NPPA]. Office Memorandum. File no. 27(2)/ 2017-Div-III/ NPPA. New Delhi: India Ministry of Chemicals and Fertilizers. Department of Pharmaceuticals. NPPA, 2018.

16 Times of India. Regulate trade margins: medical makers to gov't. 2018. https://timesofindia.indiatimes. com/india/regulate-trade-margins-device-makers-togovt/articleshow/63102937.cms (accessed Apr 2018).

17 Hindustan Times. Hospitals in Maharashtra reused 1,306 catheters, charged patients $77 \%$ of MRP, says FDA. 2017. https://www.hindustantimes.com/ mumbai-news/hospitals-in-maharashtra-reused-1306-catheters-charged-patients-77-of-mrp-says-fda/ story-Vq1edOVndIWy35mDaMu8D0.html (accessed Mar 2018).

18 The Hindu. Reused catheters: FDA plans surprise checks. 2017. http://www.thehindu.com/news/cities/ mumbai/reused-catheters-fda-plans-surprise-checks/ article18284515.ece (accessed Apr 2018).

19 Times of India. FIRs against 37 hospitals for reusing devices, patients to be reimbursed. 2017. https:// timesofindia.indiatimes.com/city/mumbai/firs-against37-hospitals-for-reusing-devices-patients-to-bereimbursed/articleshow/59764236.cms (accessed Apr 2018).

20 SlideShare. Canadian and global update on efforts to regulate "single-use" devices reprocessing. 2016. https://www.slideshare.net/CADTH-ACMTS/b8vukelich (accessed Mar 2018).

21 Mickelsen S, Mickelsen C, MacIndoe C, et al. Trends and patterns in electrophysiologic and ablation catheter reuse in the United States. Am J Cardiol 2001;87:351-3 